\title{
Cultivation of Fuzzy Cognitive Ability in Music Performance Courses
}

\author{
Yumeng $\mathrm{He}$ \\ School of Music \\ Liaoning Normal University \\ Dalian, China \\ dl_hym@126.com
}

\begin{abstract}
Fuzzification is the essential attribute of music. Human beings create, perform and appreciate music through fuzzy perception. This paper first introduced the meaning of music fuzziness and the fuzzy features of music. And then, the fuzzy features of music were analyzed from the aspects of indirectness of notes, elusiveness of sound, broadness of emotion and chaos of music. Finally, the basic framework of music fuzzy cognition research was preliminarily established by analyzing the aesthetic fuzzy features of a music work. Research shows that the fuzziness of music elements is the existence attribute of music, and the fuzziness of music expression is the formal attribute of music creation and appreciation. Therefore, only by recognizing music in the fuzzy sense of the existence and expression of music, can the fuzzy cognition of music be improved.
\end{abstract} ability

Keywords-Music art, fuzziness, fuzzy features, fuzzy cognitive

\section{INTRODUCTION}

The fuzzy theory was proposed by professor L.A. Zadeh in 1965. It has a profound influence on science and technology, culture and art, methodology and epistemology [1]. A large number of phenomena we encounter in our daily life are characterized by fuzzification. For example, the following statements are often foreseen in music appreciation: "The symphony gives one a feeling of beauty", "this music work has a high artistic level", "that opera is full of strong emotion. How charming it is!" All this casts an ineffable veil of intention on the mind. However, what is beautiful, what is tall, what is strong, and so on, usually we only have a kind of "unspeakable" feeling, which is difficult to describe with a standard.

In the field of music art research, many researchers discussed the artistic features of music from the perspective of art analysis and evaluation, and put forward different viewpoints and conclusions on the understanding and evaluation of the artistic features of music. In fact, from the analysis of the essential attributes of art, the characteristics of music art have uncertain attributes, the uncertainty is fuzzy. In other words, art itself is fuzzy, and music can be said to be the purest art, so the description of the characteristics of music art is also fuzzy.

This paper introduces how to understand and apply the

This paper is the stage research results on "Music Performance Aesthetic Fuzziness and Cognitive Ability Evaluation Research (WQ2019014)", which is the funding project in the research of humanities and social sciences by education department of Liaoning Province. concept of fuzziness in the music performance course and how to cultivate the students' fuzzy cognitive ability of music aesthetics through the fuzzy analysis of music elements and works.

\section{FUZZINESS OF MUSIC FEATURES}

\section{A. The significance of music fuzziness}

The so-called "fuzziness" is a kind of uncertainty caused by the intermediary transition between objective things. Engels pointed out: "All differences are merged in the middle stage, and all oppositions are mutually transitioned through intermediate links." From the perspective of music, we are can't find a clear interface about beautiful and unbeautiful of timbre. There is a process from quantitative change to qualitative change from one side of timbre difference to the other side. This phenomenon is called the intermediate transition of timbre difference [2]. Most concepts in music art have this mediating transition, and the uncertainty in effect judgment caused by it is called the fuzziness of music, or fuzzy music. If the way of existence and the process of expression are described by formal language, there must be fuzziness. To understand and study the process of expression, we must use fuzzy theory and method. Many problems in music art are described in the language form of music concepts, Language has the characteristics of fuzziness, such as strong and weak, fast and slow, gentle, strong and powerful, and so it is a very meaningful research work to discuss the fuzziness of music art.

In addition, music is an ideology of thoughts and emotions, which is essentially fuzzy rather than precise. However, the fuzziness and accuracy in music research and performance are the unity of opposites, interdependence, and mutual transformation. From a large number of music works, we find that the expression of music is full of fuzziness. Accuracy is often not a good indicator of true emotion, and can only be expressed through fuzziness. In the same way, fuzzy concepts can express precise meaning. In music study, fuzziness is universal and absolute. Precision is concrete, relative, and includes fuzziness. As a kind of pure art, music not only has a broad sense of artistic features but also has its own characteristics. From the perspective of the existence of art, it is a kind of meaning form of thoughts and feelings, and it is to reflect social life through shaping images. 
However, in terms of expression of thoughts and emotions and image building of social life, different music expressions have cognitive differences for different creators and receivers. Therefore, it is necessary to use fuzzy theory and method to study the artistic characteristics of music. According to the essential characteristics of music art, music is an art composed of sound material. People perceive music by hearing, which is different from other arts such as art and literature.

As we know, the sound of music is mainly musical sound, which has characteristics such as high and low, short and long, strong and weak, and timbre, etc.. Among these musical elements, although there are certain measurement standards, the artistic characteristics expressed in music works do not have strict standards for these elements. In fact, such musical features as high and low, short and long, strong and weak, and timbre are reflected in the form of interval [3]. For example,

High and low $=$ [very high, high, higher, average, lower, low, very low].

There is no strict boundary between each level of high and low, so any musical piece is fuzzy in reflecting the element of pitch. For example, the timbre itself is fuzzy, because the concept of the timbre has no explicit extension, so it can be determined according to the degree of the timbre interval= [good, relatively good, general, relatively poor, poor] when perceiving the timbre. The degree is called fuzzy degree. Therefore, how much ambiguity can be reflected vividly and truly with rich and colorful music artistic expression depends on fuzzy features in the analysis and processing of musical elements.

\section{B. Fuzzy features of music elements}

Music fuzziness is the essential attribute of music, which has the following aspects:

\section{1) Fuzzy sound feature}

Music is the art of sound, which is a special sound system beyond the natural prototype. Specifically, it is a combination of a variety of music elements, with certain life content, thoughts and feelings and organized sound process. It acts on people's hearing, triggers people's various experiences and associations, and satisfies people's aesthetic needs for music. They cannot fully explain the reasons for sound processing and organization of music elements although composers create beautiful sounds and give people spiritual satisfaction. Therefore, how to reflect the aesthetic requirements of sound is a very difficult thing. According to the principle of sound transmission, sound is a kind of wave, and the change of waveform is uncertain in terms of reflecting sound, so sound is fuzzy. In the creation of music, there is no fixed format for expressing a phenomenon and emotion with sound, which is the composer's fuzzy feeling of reality. Through the comparison between realistic emotion and fuzzy sound, acceptable sound mode and music idea are generated in the composer's mind. Therefore, the fuzzy feature analysis of music elements is not only a significant research direction of music creation, but also an important content of music aesthetic research.

\section{2) Fuzzy time feature}

Music is the transmission and display of sound in a certain time, so it is the art of time. In fact, for a music sequence within a limited time, there is no strict time standard for the part constituting each musical phrase. It is determined according to the characteristics of aesthetic perception in the performers' understanding of music works and of acoustic processing, which is fuzzy. In music performance, there is no strict standard for what time distribution reflects music characteristics. In particular, music performance time processing has this and that. In other words, the determination of music time is mediating and transitional. It is determined by the fuzzy perception of music aesthetics and the difference of the fuzzy time, so as to present the playing styles of different music players in the same music work and the personalized differences of the same players in each performance.

\section{3) The fuzziness of emotion and image}

Music is an art of image expression, while "music image" is an artistic image formed in people's mind through association, which is achieved the visualization of the music performance through the fuzzy processing of music elements on the basis of personalized fuzzy cognition of emotion. Therefore, different emotional expression fuzzy degree determines different performance individuality and style in the study of music performance. In music performance training, fuzzy method can be used to establish various emotional and image attributes, simulate emotional ambiguity with different music effects, and obtain the individuality characteristics of the emotional and the types of the artistic expression. Since music is a complex emotional system, when analyzing fuzzy emotions and image features, we must consider the characteristics of music art itself. For example, the scope of input, imagination, association and thinking in music is broad and unsuitable art [4]. There are different levels of variability in either the moment or the long term. As music is a complex emotional system, it is necessary to consider the characteristics of music art itself when analyzing the fuzzy emotional and image characteristics. For example, the investment, imagination, association and thinking range in music are broad and non-formative, and can have variability of different levels in an instant or long-term.

\section{ANALYSIS OF MUSIC FUZZY FEATURES}

This section analyzes the basic properties of fuzzy music from the aesthetic perspective of music according to the three fuzzy features of music. It mainly includes the indirect analysis of notes, the elution analysis of sound, the broad analysis of emotion and the chaos analysis of music

\section{A. Indirect analysis of notes}

As is known to all, music is obviously different from painting, dancing and poetry in that its artistic image is invisible and intangible. In other words, music has no immediacy and spatial sense of visual or tactile, no specific semantic meaning, but only auditory indirect. In fact, the single note in the music sequence has no specific meaning. It is have true music meaning when each note is organized together to form a set of music. The so-called music sets is not only the basis for composers to express their rich emotions, but also the 
basis for listeners to feel and appreciate. Therefore, music is an indirect emotional bridge between composer and listener. As individual composers and listeners, the communication and contact between them are fuzzy, abstract, incomplete and indirect due to different on life experiences and feelings towards music. Psychology believes that indirectness is dependent on the life experience of the listener, and believes that, because people's life experience is different, it is impossible to have exactly the same experience for the same concert. Therefore, it is necessary to solve the problem of indirectness of notes by the analyzing of the fuzzy features of sound, time and emotion.

\section{B. Passing analysis of the sound}

Hegel (Georg Wilhelm Friedrich Hegel, 1770-1831) said: "music has continuity and variability in time, but no space." In fact, sound cannot coexist in equivalent space and has fluidity and uncertainty [5]. The so-called transitivity of sound refers to that: the former sound passes away, the latter sound appears subsequently, and the latter sound passes away and is replaced by another sound in the process of sound appearance. Its artistic image cannot be completely determined due to the passage of sound. Therefore, the beauty of music only reflects the vague beauty of passing. In the fuzzy feature analysis of music, different process degrees are established according to the process of sound, which correspond to different degrees of fuzzy beauty. Specifically, the inner feelings of fleeting moments can be found in the fuzzy feature perception through repeated sound discrimination according to the fuzzy beauty required by different music artistic expression.

\section{Broad analysis of emotions}

The composer expresses his inner emotional world through external acoustic melody, which is meaningful only when expressing his inner feelings. People appreciate music works according to their emotional experience, and make reasonable association to the content that music itself wants to express. Music is an emotional system with personal characteristics. For the same music work, different people have different feelings. As people often say, "for a thousand viewers, there are a thousand Hamlet" (Hamlet was a tragic work created by British playwright William Shakespeare between 1599 and 1602) [6]. It can even be said that the same person's feelings towards the same piece of music may be different at different times. The listener's understanding of the composer's emotional world is both broad and fuzzy. At the same time, the emotional fuzziness shown in the voice may attract the audience in a broader field, which causes the audience to have a fuzzy sense of beauty and melt their own experience into the fuzzy beauty of music. Therefore, an important indicator to evaluate the artistic level of music is the characteristic value of the fuzzy distribution reflecting the emotional breadth [7].

The research in this section shows that music beauty is a kind of fuzzy beauty, which is the essential attribute of music art. As different people have their own aesthetic standards, both music creation and music performance should understand and master the fuzzy features of music elements. In addition, the indirectness of notes, the transience of sound and the broadness of emotion are important contents of the fuzzy feature analysis of music, as well as significant research topics in the field of music creation and music performance.

\section{ANALYSIS OF MUSIC WORKS BASED ON FUZZY COGNITION}

Psychologists have found that there is a kind of cognition, whose judgment is not based on strict logical reasoning, and the brain just keeps appearing with the concept jumping and the crossing of light and dark, which proves the situation of the problem in the unconscious process. This is called fuzzy cognition. The fuzzy cognition of music comes from the understanding and mastery of the fuzzy features of music. Generally speaking, fuzzy cognition is carried out in human brain, which is opposite to accurate cognition and has fuzzy features. The following is an analysis of the fuzzy cognition of music through specific music works.

\section{A. Introduction of music works}

The artistic characteristics of Beethoven's "moonlight" will produce different fuzzy perception for different audiences. We can deeply and comprehensively feel the connotation of this music through many times of artistic infection. In fact, the title of the piano sonata comes from the German music critic Rellstab (Ludwing Rellstab, 1799-1860) following Beethoven's death according to his own imagination, and Beethoven himself called the work "fantasy sonata" [8]

\section{B. Work analysis}

The first movement of the music is lento, $C^{\#}$ minor, 2/2 beat, trilogy [9]. At the beginning of the music, a boundless fuzzy fantasy is formed by the continuous outflow of triplets. After the fourth quarter, the first theme appears lightly in the middle section. It is meticulous and quiet, a little melancholy. As shown in the spectrum example (Fig. 1):

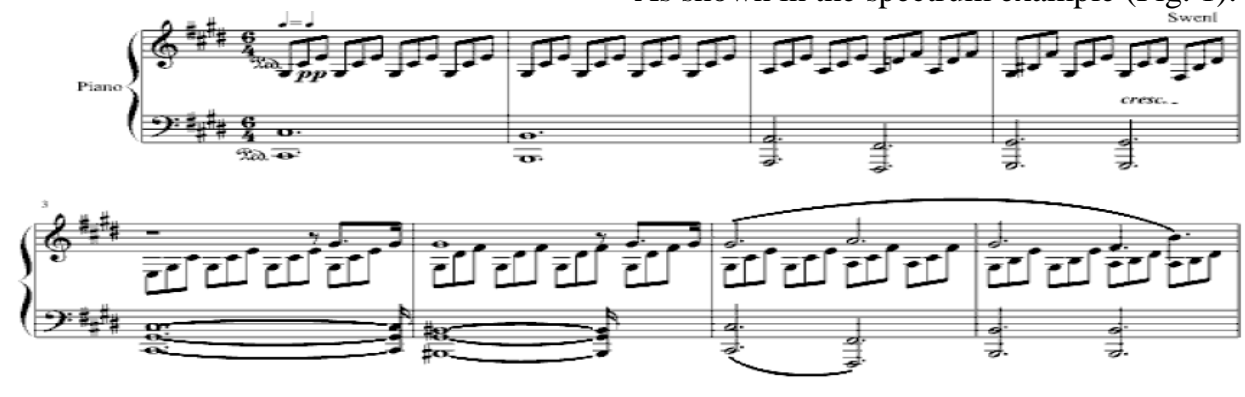

Sources: Moonlight (SONATE Op.27 No.2) Adagio sostenuto

Fig.1. The spectrum example of Beethoven's "moonlight" 
Second movement-allegretto, $\mathrm{D}^{\mathrm{b}}$ major, 3/4 beat, trilogy [9].

The first section of this movement is the theme echoed by legato and staccato, then repeated with variations. Central also remained in D major. This movement is like a warm smile left by the moment.

Third movement - presto of excitement, C minor, 4/4 beat, sonata [9]. The third movement is the climax of the whole piece, in which there is a Beethoven impulse and a tone of protest.

The climax of the whole piece expresses completely different emotions although this movement is closely related to the previous movement in tonality, showing the Beethoven impulse and protest tone.

Audience A: "It seems to me that the composer looks up at the bright moon at night, missing his hometown and relatives, and lowers his head with tears in his eyes."

Audience B: "This song is very gentle and beautiful, like a lullaby, which makes people feel like it is at night; the moonlight is sprinkled on the ground, very beautiful."

Audience C: "How gentle a song! It feels like lying in the arms of a mother. It makes people feel like standing in a beautiful place, how comfortable."

Audience D: "It was played on the piano and I thought it was beautiful, like a white swan dancing in a lake."

Audience E: "This music is three beats; I think this music is very sad, like a person in a quiet night, missing loved ones."

As Audiences have their own cognitive abilities of fuzzy features in the emotion and connotation of music, their imagination of music is stimulated.

\section{1) Imagination}

Imagination is an essential element in the process of creating music artistic beauty. However, the biggest characteristic of imagination is fuzziness. The fuzziness of imagination means that the structural elements of imagination have multiple meanings and present a state of intersection. For example, "music artistic conception" is the core category of Chinese classical music aesthetics and has become the ultimate pursuit of Chinese musicians in different times. People listen to music and expand their imagination at the same time when appreciating the symphony of destiny, and make free and reasonable association to the image of music. It is the understanding and appreciation of the fuzzy features of music whether it is the imagination combined with one's own life experience, emotion or emotion.

\section{2) Emotional transformation}

The so-called emotional transformation is emotional infiltration. The emotional transformation in music appreciation is to pay attention to the connotation of music, strengthen the power of music and purify people's soul through the way of music and people and music, so as to improve people's spiritual realm, deepen people's life philosophy and promote people to rely on the truth, kindness and beauty. As the fuzzy aesthetic feeling generated by music emotional transformation strengthens people's aesthetic taste, expands their aesthetic vision and improves their spiritual realm, the research on emotional transformation is a hot issue of music aesthetic appreciation.

\section{CONCLUSIONS}

The above research shows that music art is full of fuzziness which reflects the complexity of music itself. Because of the wide range of fields involved, the study of this problem will bring many difficulties, but it is a very promising subject. The discussion in this paper only provides the research idea in this aspect, some places have not been discussed, which needs to be introduced in another paper.

\section{ACKNOWLEDGMENT}

This study was supported by the laboratory open project (CX201901031) of Liaoning normal university, and also thanks to the funding project of Liaoning education department. Here, we would like to express our thanks to the teachers and students who participated in these two projects. They are Kang Li, Sun Wei, Yu Nuofei, Yin Meixuan, Gao Bowen, Han Shiqi, Zhang Jiahui, Xu Ningze, Yang Wenting.

\section{REFERENCES}

[1] Ping He. On the Fuzzy, Non-optimum and Trusted. Scientific and Technical Documentation Press, 2016. (In Chinese)

[2] Xiaoming Li. Fuzziness: the mystery of human understanding. People's Publishing House, 1985. (In Chinese)

[3] Mingju Wang. Fuzzy art theory. Anhui Education Press, 1992. (In Chinese)

[4] Mingju Wang. Wang Mingju's anthology: Fuzzy Aesthetics • Fuzzy Art Theory. Culture and Art Publishing House, 2012. (In Chinese)

[5] Wanqiu Jiang. Fuzziness of music art. Art Garden (Music Edition), 1997, Vol.6, 16-21. (In Chinese)

[6] Qongxin Zou. Music appreciation with fuzzy method. JOURNAL OF QINGHAI JUNIOR TEACHERS COLLEGE (Education Science). 2006 Vol.3, 83. (In Chinese)

[7] Yuntao Li. Fuzzy principle of music. Qilu Art Garden. 1998, Vol.54, pp.33-37. (In Chinese)

[8] Jiang Hong. On the Fuzziness of Lijiang Dongjing Music. The world of Music, 2004, Vol.5, pp.10-13. (In Chinese)

[9] Beethoven. Moonlight Sonata https://www.ukulelefan.com/ygzmq.html. 6/13/2019. 